F

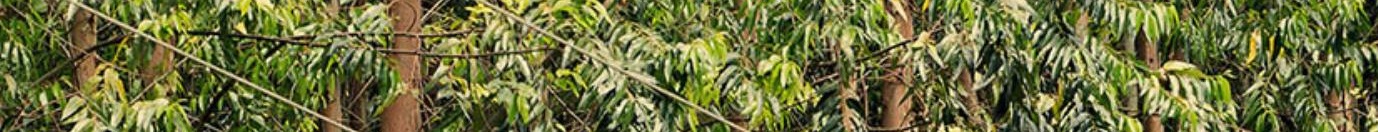

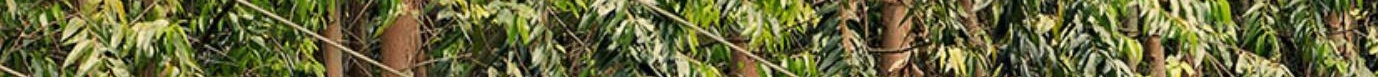
2.

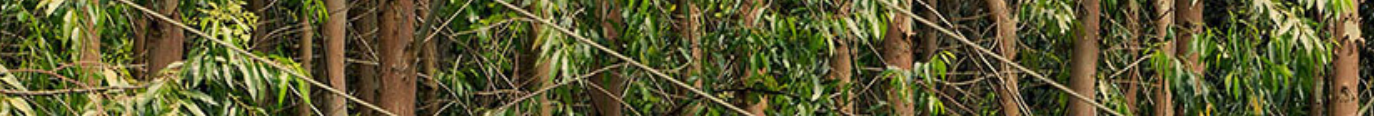
Novin: $x \rightarrow$

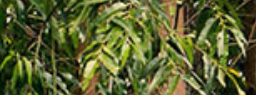

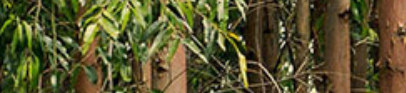

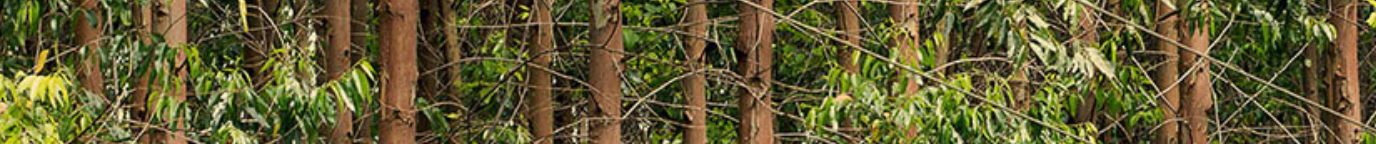

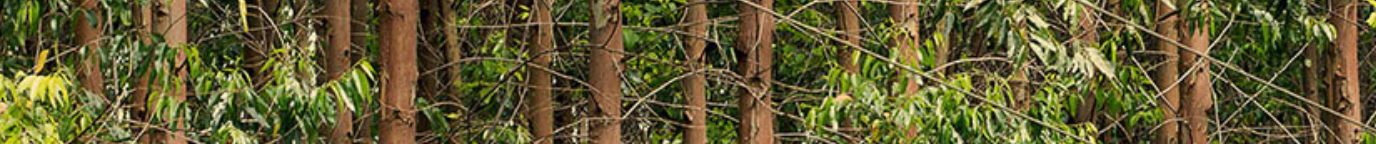

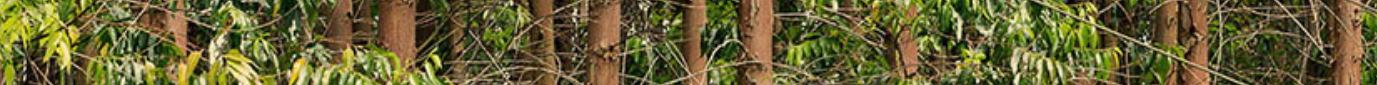

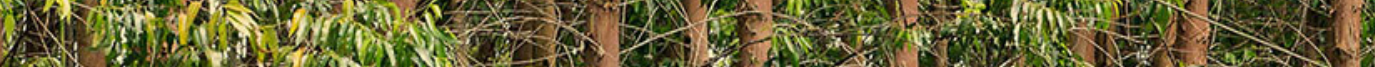
(n) 10. (1)

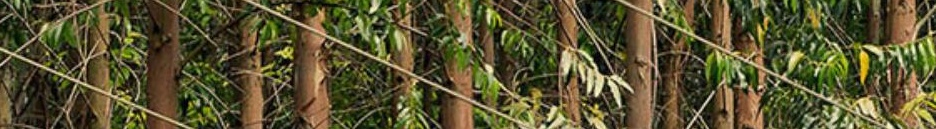
W.

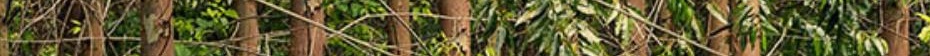

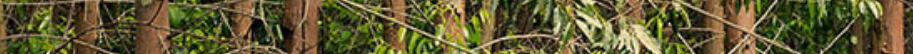
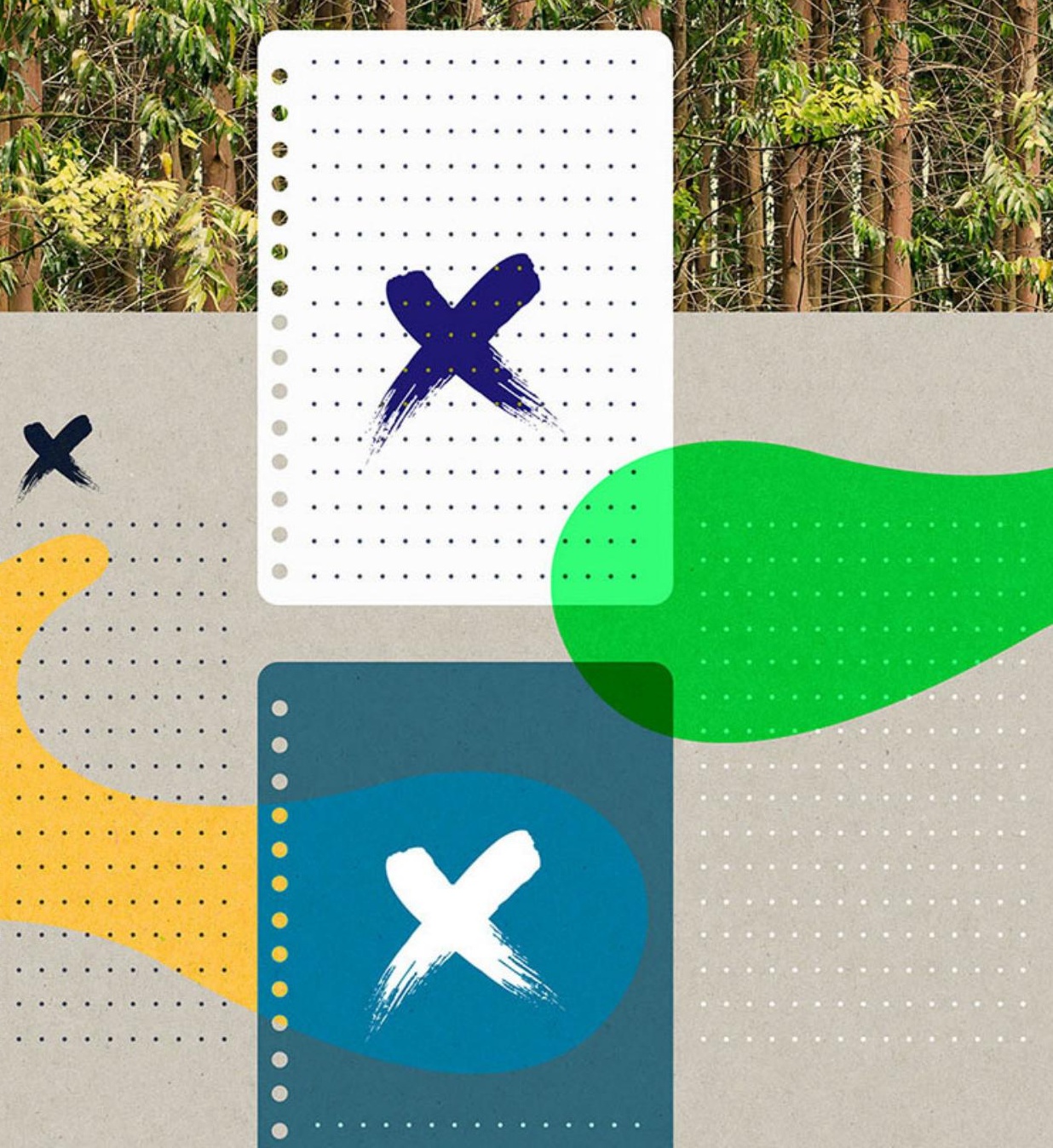


\title{
A formação do complexo florestal celulósico brasileiro
}

\author{
The formation of the Brazilian cellulosic \\ forest complex
}

Silvia Lima de Aquino*

Resumo

O artigo analisa o surgimento da indústria de papel e celulose e a consolidação do complexo celulósico florestal no Brasil. Com este intuito examina o modo pelo qual o setor se transformou de um conjunto de pequenas fábricas em um complexo agroindustrial, com uma cadeia produtiva articulada. Entende-se que a consolidação do referido complexo teve como fator central a articulação entre interesses agrários e industriais, mediados pelo Estado, que esteve e se mantém vinculado ao mesmo, ora como orquestrador de interesses; ora como investidor; e por vezes como promotor de políticas públicas. Para fundamentar a reflexão realizou-se pesquisa bibliográfica e análise de documentos relacionados ao aparato legal destinado ao setor no Brasil. Conclui-se que o uso do eucalipto e da celulose de fibra curta na fabricação de papéis, nos anos 1950, provocou uma guinada na indústria brasileira do setor, até então, muito rudimentar. Esta passou a fabricar sua matéria-prima, antes, majoritariamente, importada. Devido às condições favoráveis a eucalipto cultura e em virtude do importante papel do Estado na concessão de incentivos fiscais, por meio de legislações, planos de desenvolvimento e políticas públicas destinados não só a introdução dos plantios e a fabricação de papéis, mas, também a produção de celulose, o Brasil se tornou um dos maiores fabricantes de celulose de fibra curta do mundo.

Palavras-chave: Eucalipto; celulose; complexo florestal celulósico; Estado.

\begin{abstract}
This article analyses the emergence of the pulp and paper industry and the consolidation of the forest cellulosic complex in Brazil. To this end the article investigates how this sector that was once a set of small plants has become an agro-industrial complex with an articulated production chain. We understand that the consolidation of this complex has as its central factor the relationship between agrarian and industrial interests, mediated by the State linked to it, sometimes as an orchestrator of interests; in others as an investor; or as a promoter of public policies. We base this reflection on bibliographic research and analysis of documents related to the legal apparatus elaborated for the sector in Brazil. The paper concludes that the use of eucalyptus and short fiber pulp in papermaking in the 1950s caused a major change in the very rudimentary Brazilian papermaking industry. This sector began to manufacture its raw material, before mostly imported. Due to favourable conditions for eucalyptus cultivation and because of the important role of the state in granting tax incentives, materialized in a considerable body of legislation, public policy and development plans, for introduction of plantations and manufacturing paper, as well for the production of export pulp, Brazil has become one of the largest producers of short fiber pulp in the world.
\end{abstract}

Keywords: Eucalyptus; cellulose; cellulosic forest complex, State

\footnotetext{
* Doutora em Ciências Sociais; Mestra em Ciências Sociais; Especialista em Literatura, Memória Cultural e Sociedade; Bacharel em Ciências Sociais; Licenciada em Geografia. Professora Adjunta da Universidade Federal do Rio Grande do Sul/ Campus Litoral Norte/ Departamento Interdisciplinar no Programa de Pós-Graduação em Dinâmicas Regionais e Desenvolvimento, no Bacharelado Interdisciplinar em Ciência e Tecnologia e no Bacharelado em Desenvolvimento Regional. https://orcid.org/0000-0002-7782-4345. E-mail: silvia.aquino@ufrgs.br

http://dx.doi.org/10.51861/ded.dmv.1.001
} 


\section{INTRODUÇÃO}

O artigo origina-se da tese de doutorado denominada "Sobre agricultores, cultivo de eucalipto e estratégias agroindustriais: Resistir e adaptar-se ao sistema de produção integrada” e tem como objetivo central analisar como se deu o surgimento e a consolidação do complexo celulósico florestal no Brasil. Com o intuito de diferenciar a conformação atual deste segmento agroindustrial daquela existente em seu início, o trabalho utilizará a noção de “complexo florestal celulósico”. Tal diferenciação se explica porque - apesar da primeira fábrica de papel ter sido instalada no país em 1852 - até os anos 1950 este segmento era composto apenas por pequenas plantas produtoras de papel, por meio de celulose importada e por uma quantidade ínfima de produção de celulose. Somente a partir de meados de 1950, por meio dos primeiros grandes incentivos concedidos pelo governo federal, é que esta indústria começa a despontar e a experimentar um processo de transformação onde passa a produzir sua própria matéria-prima (FAILLLACE, 1996; LOPES \& CONTADOR, 1998).

Diferenciar estas etapas da constituição da indústria de celulose e papel no Brasil é fundamental para entender: (1) os rumos tomados pelo setor desde o seu surgimento até o período mais recente; (2) o papel do Estado neste processo; (3) a maneira com a qual este segmento transformou-se - de um conjunto de pequenas fábricas relativamente desorganizadas - em um setor industrial importante, com uma cadeia produtiva articulada e com propriedade de grandes extensôes de terras; (4) seus impactos e interferências no meio rural de várias regiões do país. Ao mesmo tempo, tal diferenciação permitirá compreender o papel deste segmento como parte do processo de industrialização do país e de modernização de sua agricultura.

O termo "complexo florestal celulósico", elaborado por Faillace (1996), denota duas fases na atividade agroindustrial produtora de papel e celulose no Brasil. A primeira relaciona-se ao nascimento e estruturação da indústria de papel no país, sob o predomínio do capital nacional, tal fase é compreendida entre 1891 a 1960. A segunda fase refere-se à consolidação do complexo florestal e compreende o período que vai de 1960 a 1991. Tal processo desdobra-se a partir da articulação entre interesses agrários (atividade florestal) e industriais, mediados pelo Estado, por intermédio da implementação de políticas públicas. Na perspectiva do autor “(...) o complexo florestal pode ser entendido como o espaço no qual se orquestram os interesses privados e se elaboram e executam as políticas públicas” (SOTO, 1992, p. 179). Faillace (1996) acrescenta ao termo "complexo florestal" a palavra "celulósico", de modo a evidenciar, que em sua abordagem, há uma preocupação central com o segmento agroindustrial produtor de papel e celulose. 
Pedreira (2008) faz uma ressalva que, de certo modo, se complementa a observação de Soto (1992), a respeito do complexo florestal. Enquanto este autor fala de duas principais fases na atividade agroindustrial produtora de papel e celulose, Pedreira (2008) divide a atividade florestal no Brasil - que é fundamental na produção de matéria-prima para este segmento industrial - em duas fases. A primeira vai do descobrimento do país até 1965, e é caracterizada, inicialmente, pelo extrativismo nômade e, posteriormente, pelas primeiras experiências de plantios florestais homogêneos. A segunda fase se inicia em 1966 e vai até os dias de hoje e, segundo a autora, pode ser caracterizada pelo crescimento, intensificação e consolidação da articulação entre atividade industrial e atividade florestal, bem como pela larga ampliação do monocultivo de árvores exóticas, em especial no período de vigência dos incentivos fiscais para o segmento, que se deu entre 1966 e 1988.

Assinaladas as devidas especificidades, de forma geral, estes autores entendem o segmento industrial produtor de papel e celulose de maneira mais ampla. Desta maneira, explicam que a opção pela noção "complexo" indica a necessidade de considerar, além das atividades técnico-econômicas, a articulação existente entre os interesses privados e estatais. Assim, destacam que o Estado brasileiro esteve e se mantém vinculado ao complexo florestal celulósico, ora como orquestrador de interesses; por vezes como investidor; ou então na condição de promotor de políticas públicas. Tal relação entre Estado e setor privado teve grande relevância para tornar esta indústria competitiva no mercado mundial.

Como este trabalho funda-se, em certa medida, em uma descrição histórica, utiliza como ferramentas metodológicas as estratégias de revisão bibliográfica (VOLPATO, 2007) e pesquisa documental, assim, entende documentos como q "evidências físicas, peças produzidas não especificamente para o propósito da pesquisa, mas, disponíveis para serem exploradas pelo investigador” (MAY, 200, p.205).

Ressalta-se que o artigo divide-se em três partes, além desta introdução e das consideraçốes finais. Na primeira parte são abordados os caminhos que levaram a introdução do cultivo de eucalipto no Brasil. Na seção seguinte, analisam-se as condiçôes que favoreceram a consolidação do eucalipto como matéria-prima principal para a indústria fabricante de papel e celulose. $\mathrm{Na}$ terceira parte examinam-se os fatores responsáveis pela integração entre o cultivo de árvores exóticas e agroindústrias, cujo resultado foi a conformação do complexo florestal celulósico propriamente dito, destacando o papel do Estado, sobretudo a partir da criação de políticas públicas direcionadas ao referido segmento. Por fim, retoma-se, ainda que de maneira breve, nas consideraçóes finais, os principais pontos debatidos 


\section{A INTRODUÇÃO DO EUCALIPTO NO BRASIL E O SURGIMENTO DO PRIMEIRO MARCO LEGAL PARA FLORESTAS}

As primeiras mudas de eucalipto foram introduzidas no Brasil, entre 1824 e 1829, no Jardim Botânico do Rio de Janeiro. Desde as primeiras décadas do século XIX até o início do século XX o eucalipto se disseminou pelo Brasil como uma curiosidade, como um elemento decorativo, como quebra vento, pelas suas possíveis propriedades sanitárias ou ainda pelo seu aroma característico (ANDRADE, 1961). A possibilidade de utilização das espécies em uma função econômica passou a existir no início do século XX, quando a Companhia Paulista de Estradas de Ferro - CPEF buscava uma espécie para atenuar uma possível escassez futura de matéria-prima para a produção de dormentes e carvão. Desta maneira a empresa criou um departamento de serviço florestal e contratou o engenheiro agrônomo Edmundo Navarro de Andrade como diretor, com a função de encontrar espécies que conseguissem se adaptar ao ambiente local (MARTINI, 2004; FANZERES et al., 2005).

Com este intuito, entre 1904 e 1909, Andrade realizou muitas comparações entre o eucalipto e diversas outras espécies arbóreas, dentre elas a peroba (Aspidospermapolyneuron), Cabreúva(Myrocarpusfrondosus), jequitibá(Carinianalegali), jacarandá paulista (Machaeriumvillosum) e pinheiro-do-paraná (Araucariaangustifolia). Nestas pesquisas o eucalipto (Eucalyptus) destacou-se como a mais produtiva e foi escolhido como matéria-prima para a confecção de dormentes para CPEF, no ano de 1908. A partir de 1909 a CPEF adquiriu terras, criou diversos hortos e iniciou o cultivo de eucalipto em escala comercial (MORA \& GARCIA, 2000). A experiência com o cultivo de eucalipto conduzida por Edmundo Navarro de Andrade marcou o início da silvicultura no Brasil (DIAS, 2007).

Além de cultivar eucaliptos para a produção de dormentes, a CPEF passou a comercializar a madeira provinda desta espécie para a construção civil. Para tanto, adquiriu terras às margens das ferrovias. Ao mesmo tempo, incentivou o cultivo de eucalipto em propriedades particulares próximas às ferrovias e auxiliou diversas pessoas no país, interessadas em cultivar a espécie. Fornecia publicaçóes, orientaçóes ou ainda facilitava aquisição de sementes de eucalipto, que eram vendidas a preços reduzidos (MARTINI, 2004).

Quando em 1919, a CPEF iniciou o plano de eletrificação de parte de suas linhas, passou a utilizar o eucalipto na fabricação dos postes e moiróes. Ademais, após testes de calorimetria o eucalipto passou também a ser utilizado como lenha para as caldeiras das locomotivas cujas linhas não eram eletrificadas (MARTINI, 2004). Depois da experiência da CPEF 
a indústria siderúrgica também começou a cultivar grandes extensões de terra com eucalipto, para abastecer seus fornos, a exemplo da empresa Belgo-Mineira, em Minas Gerais (QUEIROZ \& BARICHELO, 2008).

De acordo com Dias (2007), a CPEF estava interessada em ingressar no mercado de fabricação de papel no futuro. Por isso, estimulou as pesquisas de Andrade a respeito das possibilidades de utilização do eucalipto na produção de celulose destinada a este segmento industrial. Deste modo, em 1925 o pesquisador viajou aos Estados Unidos para testar a utilização do eucalipto na fabricação de celulose. A experiência foi bem sucedida, pois, o pesquisador conseguiu produzir celulose de eucalipto por meios mecânicos.

A partir dos anos 1930, devido à crescente importância da silvicultura para a produção industrial, bem como, em virtude da crescente área cultivada com eucalipto, emerge no Brasil um longo debate entre conservacionistas e desenvolvimentistas em relação à necessidade de criação de um código florestal no país. Os primeiros denunciavam o processo de desmatamento ocorrido nas florestas nativas brasileiras em razão do modelo de desenvolvimento adotado pelo país e defendiam a necessidade de sua proteção. O segundo grupo salientava a necessidade de modernização do país, através de um amplo processo de industrialização, e via os danos ambientais decorridos desse processo como inerentes e inevitáveis (DIAS, 2007). Os movimentos conservacionistas lutavam pela “(...) necessidade de reorganização da exploração florestal no Brasil, e estabeleceram importantes referenciais para a construção de uma nova política ambiental" (MEDEIROS, 2006, p.50). Tais movimentos pressionavam o poder público para a criação de um instrumento legal de proteção à natureza.

Como resultado desta disputa, apesar das incisivas críticas de diversos setores, a exemplo da CPEF, o primeiro Código Florestal Brasileiro foi instituído no governo Getúlio Vargas, pelo Decreto n.23.793, de 23 de janeiro de 1934, sendo o Instituto Nacional do Pinho (INP) o órgão encarregado, posteriormente, de fazer cumprir suas deliberaçôes (BACHA, 2004). Tal código, juntamente com a Constituição Federal de 1934 consolidaram algumas das aspiraçốes conservacionistas. Segundo Medeiros (2006) o Código Florestal de 1934:

(...) Definiu objetivamente as bases para a proteção territorial dos principais ecossistemas florestais e demais formas de vegetação naturais do país. Ele tinha como principais objetivos legitimar a ação dos serviços florestais, em franca implementação em alguns estados brasileiros desde o final do século XIX, além de regularizar a exploração do recurso madeireiro, estabelecendo as bases para sua proteção. (...) Ele declarava de "interesse comum a todos os habitantes do país" o conjunto das florestas existentes e demais formas de vegetação (...). (MEDEIROS, 2006, p.50). 
Além disso, neste código, instituído com a presença do próprio Andrade, que na época representava o Ministério de Estado da Agricultura ${ }^{1}$, foram criadas quatro categorias para classificação das florestas presentes no país, descritas no artigo $3^{\circ}$. do referido Código: a) protetoras; b) remanescentes; c) modelo e d) de rendimento. De acordo com esta classificação, o atual monocultivo de eucalipto seria enquadrado nas classes "modelo" e "rendimento" ( BRASIL, 1934). Neste Código foram colocadas limitações às propriedades privadas, segundo o tipo de floresta nelas existente. Além disso, foi regulada a exploração das florestas de domínio público e privado. Também foi instituída a estrutura de fiscalização das atividades florestais, as penalidades, infrações e os respectivos processos aos infratores.

Entretanto, como destaca Gonçalves (2006), embora as posiçóes conservacionistas tivessem culminado na criação de uma legislação específica como o Código Florestal de 1934, também fortaleceram o discurso de grupos ou indivíduos ligados ao segmento industrial, naquilo que tange a implantação do monocultivo de árvores exóticas, em substituição a utilização de espécies nativas, em atividades industriais. Estas posições se materializaram em alguns artigos do próprio Código, como o apresentado abaixo, pelo qual o governo federal passou a exigir também que as indústrias dependentes de recursos florestais produzissem a sua própria matéria-prima.

Art. 26. As empresas siderurgicas e as de transporte, no gozo de concessão ou de outro favor especial, são obrigadas a manter em cultivo as florestas indispensaveis ao supprimento regular da lenha ou do carvão de madeira, de que nescessitarem em areas estabelecidas de accôrdo com a autoridade florestal. Será dispensado o cultivo das florestas nas regiôes de extensas florestas virgens, determinadas pela repartição florestal competente (BRASIL, 1934).

Apesar de se constituir em uma legislação inédita e pioneira no país, os mecanismos estabelecidos pelo Código Florestal de 1934 foram pouco praticados. O próprio governo não alocou recursos para cumprir aquilo estabelecido na legislação. Isso se deveu ao modelo de desenvolvimento adotado pelo país naquela época, que privilegiou a criação de atividades industriais e urbanas, além da expansão da agropecuária para gerar divisas para a industrialização (BACHA, 2004). Assim, por um lado, a década 1930 foi marcada pelo estabelecimento de uma legislação florestal específica, algo inédito no país e fruto de uma demanda colocada por setores da sociedade contrários à degradação dos ecossistemas florestais. Por outro lado, este período também pode ser caracterizado pela implantação de uma política direcionada ao controle dos recursos madeireiros e das florestas, entendidos como insumos direcionados ao setor industrial, portanto, como recursos subordinados às necessidades da produção. 


\section{A CONSOLIDAÇÃO DO EUCALIPTO COMO MATÉRIA-PRIMA PARA A PRODUÇÃO DE CELULOSE E OS PROGRAMAS DE INCENTIVO GOVERNAMENTAIS}

As pesquisas realizadas por Andrade a respeito do eucalipto e as suas possibilidades de utilização influenciaram empresas brasileiras do setor siderúrgico e do setor papeleiro a investirem no cultivo. A Companhia Melhoramentos, por exemplo, começou a plantar eucalipto no ano de 1912, com o intuito de obter lenha para seus fornos de cal e cerâmica². Entre os anos 1940 e 1950, com o aumento da produção de aço e de ferro-gusa, o eucalipto passou a ser utilizado como principal fonte de combustível para esta atividade industrial ${ }^{3}$. A preferência deste segmento pelo eucalipto contribuiu para a expansão das áreas de cultivo da planta - até então concentradas no estado de São Paulo - para outros estados, tais como Minas Gerais, Bahia, Mato Grosso, Paraná, Maranhão e Espírito Santo (GONÇALVES, 1999 apud PEDREIRA, 2008; FAILLACE, 1996b).

Ainda na década de 1950, com a introdução do Plano de Metas, no governo de Juscelino Kubitschek (1956-1960), seguindo o modelo clássico de substituição das importaçóes, a indústria produtora de papel no Brasil passou a receber seus primeiros investimentos significativos (LOPES \& CONTADOR, 1998 $)^{4}$. Neste período o Brasil era praticamente autossuficiente na produção de papel, exceto de papel de imprensa, mas, ainda importava mais de $70 \%$ da celulose de que precisava, o que elevava o preço do produto final (HILGEMBERG \& BACHA, 2000).

O setor de papel e celulose compunha a meta 24 do Plano de Metas e sua leitura denota a clara intenção governamental em desenvolver o segmento de fabricação de papel, de modo a atender a demanda do mercado consumidor interno. Para tanto, o Plano delimitou dois principais objetivos para este segmento. O primeiro colocava a necessidade de integração da produção de celulose à de papel. $\mathrm{O}$ segundo pretendia tornar o país autossuficiente na produção de celulose. Para que isso fosse possível, o governo deu início à criação de diversas iniciativas como medidas tarifárias e creditícias, majoritariamente, através do Banco Nacional de Desenvolvimento Econômico BNDE (LOPES \& CONTADOR, 1998).

Todavia, apesar dos primeiros testes com o eucalipto, até a década de 1950 a indústria de papel utilizava como matéria prima a Arancaria angustifolia, vinda do Sul do país, para produzir apenas uma pequena parte da celulose que utilizava. Neste sentido, este segmento se configurava em uma indústria de pequeno porte que pagava altos preços por sua matéria-prima, pois precisava concorrer com as empresas que exportavam madeiras serradas e aglomeradas e, ao mesmo tempo, com a crescente demanda madeireira, 
decorrente do crescimento e urbanização, centrada em São Paulo. Em virtude da competição por busca de madeiras, os esforços de pesquisas para promover a substituição das fibras longas no fabrico de celulose se intensificaram, sendo que o eucalipto já apresentava grande potencial (FAILLACE, 1996).

Para tornar o Brasil autossuficiente na produção de celulose, conforme diretriz estabelecida no Plano de Metas, era necessário desenvolver uma tecnologia, em escala comercial, capaz de aproveitar o eucalipto como matériaprima, dada a sua rapidez de crescimento. Daí a explicação para os empresários buscarem parceria e recursos governamentais.

A utilidade do eucalipto na produção de celulose só foi de fato reconhecida no final da década de 1950, quando uma empresa do estado de São Paulo, chamada "Indústria de Papel Leon Feffer", preocupada com a escassez de celulose importada que poderia ocorrer em virtude da II Guerra Mundial, começou a investigar as potencialidades da celulose de bambu até chegar à tecnologia de produção de celulose de eucalipto em escala industrial. Em 1955 a "Indústria de Papel Leon Feffer" adquiriu a indústria de papel Euclides Damiani S/A, localizada também no estado de São Paulo, na cidade de Suzano. Com isso, depois de um ano, passou a se chamar Companhia Suzano de Papel e Celulose (HASSE, 2006).

Em 1956 a Companhia Suzano de Papel e Celulose inaugurou uma fábrica piloto de produção de celulose a partir do eucalipto. Entre a segunda metade dos anos 1950 até o início da década de 1960, esta empresa conduziu uma série de pesquisas nos laboratórios da Universidade da Califórnia, que atrelada à pesquisa básica realizada no Brasil pelo Instituto de Pesquisas e Estudos Florestais - IPEF5 que proporcionou a fabricação de um papel com $100 \%$ de celulose de eucalipto. Em 1961, com o sucesso na fabricação, a empresa passou a produzir em escala industrial papéis com esta composição ${ }^{6}$. Deste modo, cessou a importação de celulose, passando a fabricar papeis com a pasta feita através da fibra curta do eucalipto produzido no país (HASSE, 2006; MORA \& GARCIA, 2000).

Conforme Soto (1992), a fabricação de papel a partir da celulose de fibra curta oriunda do eucalipto configurou-se em um processo de inovação crucial para o avanço e desenvolvimento da indústria de papel e celulose nacional. Este foi o mais importante processo de inovação tecnológica registrado pela indústria brasileira deste segmento, onde, comumente, a maioria das inovaçôes e máquinas incorporadas ao processo produtivo surge por meio de pesquisas conduzidas por indústrias internacionais.

Outra inovação estratégica deste segmento agroindustrial, mas, no setor agrícola consistiu na uniformização e aumento da produtividade dos plantios de eucalipto. Estes resultados foram alcançados por meio de pesquisas 
que tinham o objetivo de obter madeira em um tempo e com um custo de produção reduzidos, organizadas na Escola Superior de Agricultura Luiz de Queiroz - ESALQ pertencente a Universidade De São Paulo - USP, e realizada com financiamentos públicos pelo IPEF ${ }^{7}$. No que concerne à indústria, a principal inovação repousou na fabricação de tramas de fibras curtas que tornavam o papel mais resistente, cuja pesquisa foi realizada pelo Instituto de Pesquisas Tecnológicas - IPT em parceria com as empresas fabricantes de papel e celulose e de máquinas destinadas a este segmento.

\section{A INTEGRAÇÃO ENTRE O CULTIVO DE ÁRVORES EXÓTICAS E AGROINDÚSTRIAS: A FORMAÇÃO DO COMPLEXO FLORESTAL CELULÓSICO}

A inovação da legislação estimulada pelo Plano de Metas, bem como a inovação organizativa possibilitada pela legislação, associando Universidades, empresas e governo, criou uma tecnologia capaz de gerar celulose a partir da fibra curta de eucalipto, processo inédito mundialmente. Tal inovação deu a largada para a introdução em larga escala do cultivo desta planta em diversas regióes brasileiras. Deste modo, assinalou o início de uma nova fase da silvicultura praticada no país e à ascensão de um novo modelo institucional no setor produtor de papel e celulose, a partir de meados dos 1960 . Esta nova conformação caracterizada: 1) pela articulação, antes praticamente inexistente, entre o segmento produtor de madeira e o segmento industrial; 2) pela modernização das fábricas e expansão de sua capacidade industrial; 3) pela ascensão de um novo segmento fabricante de celulose de mercado; originou o que Faillace (1996) denomina complexo florestal celulósico.

Cabe ressaltar, que esta articulação na produção de papel e celulose, gestada a partir dos anos 1960, não foi desencadeada apenas por uma iniciativa pioneira e independente das elites agrárias e industriais envolvidas neste segmento, mas simestá associada a um grande programa de incentivos e investimentos governamentais, materializados em diversas políticas públicas de cunho financeiro, institucional e creditício, que tiveram início a partir de meados da década de 1960 e se intensificam na década 1970, no âmbito da ditadura civil-militar.

Os governos estaduais sediados nessa conjuntura, a partir da conformação de uma ampla aliança entre a burguesia nacional, internacional e o Estado brasileiro, privilegiaram em suas políticas o grande capital, bem como uma estratégia de modernização que objetivava introduzir o país na esfera do capitalismo internacional (FAILLACE, 1996). É justamente neste período, conforme Delgado (1985), que o processo de modernização agrícola no país 
torna-se mais dinâmico e abrangente, favorecendo uma maior aproximação entre indústria e agricultura e, por conseguinte, o surgimento ou reestruturação de diversas indústrias processadoras de matérias-primas produzidas no campo, as chamadas agroindústrias.

Este novo modelo de silvicultura teve como principal marco legal o segundo Código Florestal brasileiro, estabelecido pela Lei n. ${ }^{\circ} 4.771$ de 15 de fevereiro de 1965. Este Código se configurou em um importante instrumento regulador de atividades florestais, uma vez que declarou em seu Art. $1^{\circ}$ as florestas existentes no território nacional como bens de interesse comum a toda sociedade.

Art. $1^{\circ}$ As florestas existentes no território nacional e as demais formas de vegetação, reconhecidas de utilidade às terras que revestem, são bens de interesse comum a todos os habitantes do País, exercendo-se os direitos de propriedade, com as limitações que a legislação em geral e especialmente que esta Lei estabelecem.

O Código Florestal de 1965 possuía duas linhas básicas e diferenciadas de atuação em relação à política florestal: proteção e desenvolvimento florestal. $\mathrm{Na}$ perspectiva deste artigo, a última pode ser entendida como o desenvolvimento de açôes visando à expansão de um segmento florestal comercial, baseado no monocultivo de espécies arbóreas exóticas. No que concerne ao desenvolvimento florestal, mais minucioso que o anterior em relação ao monocultivo de espécies arbóreas exóticas, conforme observa-se nos parágrafos citados abaixo, este Código 1) liberou a exploração do que chamou de "florestas plantadas"; 2) às declarou imunes a qualquer tipo de tributação; 3) determinou que o preço da terra não poderia se elevar em virtude deste tipo de plantação; 4) e estabeleceu diretrizes para a concessão de estímulos tributários e fiscais àqueles que investissem nessa atividade, como a isenção do imposto territorial:

As florestas plantadas ou naturais são declaradas imunes a qualquer tributação e não podem determinar, para efeito tributário, aumento do valor das terras em que se encontram (BRASIL, 1965).

$\S 1^{\circ}$ Não se considerará renda tributável o valor de produtos florestais obtidos em florestas plantadas, por quem as houver formado (BRASIL, 1965).

$\S 2$ o As importâncias empregadas em florestamento e reflorestamento serão deduzidas integralmente do imposto de renda e das taxas específicas ligadas ao reflorestamento (BRASIL, 1965).

Art. 39. Ficam isentas do imposto territorial rural as áreas com florestas sob regime de preservação permanente e as áreas com florestas plantadas para fins de exploração madeireira (BRASIL, 1965). 
Parágrafo único. Se a floresta for nativa, a isenção não ultrapassará de $50 \%$ (cinqüenta por cento) do valor do imposto, que incidir sobre a área tributável (BRASIL, 1965)..

Art. 41. Os estabelecimentos oficiais de crédito concederão prioridades aos projetos de florestamento, reflorestamento ou aquisição de equipamentos mecânicos necessários aos serviços, obedecidas as escalas anteriormente fixadas em lei (BRASIL, 1965).

Parágrafo único. Ao Conselho Monetário Nacional, dentro de suas atribuiçôes legais, como órgão disciplinador do crédito e das operações creditícias em todas suas modalidades e formas, cabe estabelecer as normas para os financiamentos florestais, com juros e prazos compatíveis, relacionados com os planos de florestamento e reflorestamento aprovados pelo Conselho Florestal Federal (BRASIL, 1965).

Além dessas disposições, o Código Florestal de 1965 ampliou a cláusula do código anterior em relação ao plantio de árvores por segmentos consumidores de madeira. Assim, determinou que todos os consumidores de madeira, independente de seu porte, realizassem a reposição florestal, além de conservarem plantios próprios para seu consumo. Ademais, o Código Florestal de 1965 fez referência à possibilidade de segmentos consumidores de madeira, tal qual a indústria de papel e celulose, realizarem plantios de árvores em propriedades de terceiros.

Art. 20. As empresas industriais que, por sua natureza, consumirem grande quantidades de matéria prima florestal serão obrigadas a manter, dentro de um raio em que a exploração e o transporte sejam julgados econômicos, um serviço organizado, que assegure o plantio de novas áreas, em terras próprias ou pertencentes a terceiros, cuja produção sob exploração racional, seja equivalente ao consumido para o seu abastecimento (BRASIL, 1965).

Art. 21. As empresas siderúrgicas, de transporte e outras, à base de carvão vegetal, lenha ou outra matéria prima florestal, são obrigadas a manter florestas próprias para exploração racional ou a formar, diretamente ou por intermédio de empreendimentos dos quais participem, florestas destinadas ao seu suprimento (BRASIL, 1965).

Para garantir o cumprimento das disposiçóes estabelecidas, passadas algumas décadas da criação do Código Florestal de 1965, o governo federal publicou um regulamento através do Decreto nº 97.628 de 10 de abril de 1989. Entre as diretrizes deste regulamento havia uma disposição que colocava, de maneira direta, a necessidade de integração floresta/indústria e a possibilidade de aquisição de madeiras pelo segmento industrial através de programas de fomento florestal ${ }^{8}$. 
Parágrafo único. A comprovação do atendimento ao disposto neste artigo será realizada mediante a apresentação de um Plano Integrado Floresta-Indústria (PIFI), demonstrativo de fontes de suprimento de matéria-prima florestal voltada ao abastecimento da unidade consumidora, conforme metodologia, critérios e parâmetros estabelecidos pelo Instituto Brasileiro do Meio Ambiente e dos Recursos Naturais Renováveis (BRASIL, 1989).

Art. $3^{\circ} \mathrm{O}$ Plano Integrado Floresta-Indústria (PIFI), no que se refere à formação do estoque de matéria-prima, será composto por quaisquer das modalidades a seguir discriminadas:

a) pela apresentação de projetos técnicos de reflorestamento e/ou levantamento circunstanciado de área plantada;

b) pela execução do plano de manejo de rendimento sustentado da área sob exploração;

c) pela execução e/ou participação em programas de Fomento Florestal aprovados pelo Instituto Brasileiro do Meio Ambiente e dos Recursos Naturais Renováveis (BRASIL, 1989).

Se do ponto de vista legal o Código Florestal de 1965 estabeleceu as diretrizes para a concessão de incentivos aos setores que investissem no monocultivo de árvores exóticas destinado ao segmento industrial, do ponto de vista financeiro, papel fundamental teve a instituição da Lei n. o 5.106, de 2 de setembro de 1966, que regulamentou os incentivos fiscais previstos pelo Código. Esta Lei permitia que tanto as pessoas físicas quanto jurídicas abatessem do imposto de renda as importâncias empregadas em florestamento ou reflorestamento. Deste modo, favorecia a transferência de uma grande quantia de recursos públicos para o setor privado. Estes abatimentos seriam concedidos, inclusive, se o investidor introduzisse árvores para fins comerciais em propriedades de terceiros.

Art. 1o As importâncias empregadas em florestamento e reflorestamento poderão ser abatidas ou descontadas nas declaraçóes de rendimento das pessoas físicas e jurídicas, residentes ou domiciliados no Brasil, atendidas as condiçóes estabelecidas na presente lei (BRASIL, 1965).

$\S 3$ o As pessoas jurídicas poderão descontar do impôsto de renda que devam pagar, até $50 \%$ (cinqüenta por cento) do valor do impôsto, as importâncias comprovadamente aplicadas em florestamento ou reflorestamento, que poderá ser feito com essências florestais, árvores frutíferas, árvores de grande porte e relativas ao ano-base do exercício financeiro em que o impôstofôr devido (BRASIL, 1965).

Art. 2ํ As pessoas físicas ou jurídicas só terão direito ao abatimento ou desconto de que trata êste artigo desde que: 


\section{(...)}

b) tenham seu projeto prèviamente aprovado pelo Ministério da Agricultura, compreendendo um programa de plantio anual mínimo de 10.000 (dez mil) árvores;

c) o florestamento ou reflorestamento projetados possam, a juízo do Ministério da Agricultura, servir de base à exploração econômica ou à conservação do solo e dos regimes das águas (BRASIL, 1965).

Art. 4o Para os fins da presente lei entende-se como despesas de florestamento e reflorestamento aquelas que forem aplicadas diretamente pelo contribuinte ou mediante a contratação de serviços de terceiros, na elaboração do projeto técnico, no preparo de terras, na aquisição de sementes, no plantio, na proteção, na vigilância, na administração de viveiros e flores e na abertura e conservação de caminhos de serviços (BRASIL, 1965).

Cabe ressaltar que a Lei n. 05.106 foi estabelecida em consonância com as estratégias adotadas pelo Estado brasileiro desenvolvimentista dos anos 1960 e 1970 e fazia parte de uma política agroindustrial nacional. Seu objetivo central era induzir o setor privado a investir em um segmento que exige um longo período de amortização dos investimentos, de modo a garantir o fornecimento de matéria-prima a baixo custo para indústrias, cuja expansão, na avaliação do Estado, contribuiria para o crescimento do país.

Soto (1992) observa que sob o estímulo da referida Lei, entre 1966 e 1970, surgiu um novo segmento industrial, composto por pequenas e médias empresas especializadas no monocultivo de árvores exóticas. Estas, por sua vez, foram responsáveis por impulsionar a atividade no Brasil. Neste período, cerca de $80 \%$ dos "reflorestamentos" introduzidos no país advinham de incentivos fiscais concedidos pelo governo. Este número demonstra o fundamental papel do Estado na consolidação do complexo florestal celulósico brasileiro. Diante disso, Faillace (1996, p. 7) avalia que a Lei n.o 5.106 consistiu "na mais importante iniciativa política articulada externamente ao setor, como instrumento de política econômica, mas com larga repercussão na área florestal produtiva”.

A concessão de incentivos fiscais destinados à expansão do complexo florestal celulósico não só prosseguiu como se intensificou na década de 1970 . Os sucessivos incentivos governamentais destinados não apenas ao monocultivo de árvores exóticas, mas também a modernização, ampliação e implantação de indústrias fabricantes de papel e celulose provocou significativa transformação no setor. Transformação esta já perceptível nos anos 1973, onde $52 \%$ dos fabricantes brasileiros de papel possuíam produção superior a vinte toneladas/dia. Em 1967, apenas $28 \%$ se encontravam nesse patamar (JUVENAL \& MATTOS, 2003). 
Ademais, enquanto em 1967 havia somente quatro fabricantes de papel com capacidade acima de cem toneladas/dia, em 1973 quatorze produtores já alcançavam esta média. Entre 1957 e 1973, a produção de papel aumentou quatro vezes e o consumo três vezes. Em 1967, 10\% das empresas produtoras de celulose possuíam capacidade superior a cem toneladas/dia, ao passo que em 1973, 20\% das empresas atingiram esta capacidade. Além disso, devido ao estabelecimento das escalas mínimas de produção pelo BNDE e dos novos investimentos concedidos entre 1957 e 1973, a produção de celulose e pastas de alto rendimento 9 aumentou quase sete vezes, enquanto o consumo cresceu 3,5 vezes, propiciando o início das exportaçôes (JUVENAL \& MATTOS, 2003).

Os dados apresentados por Juvenal e Mattos (2003) abordam apenas o início dos anos 1970, entretanto, os investimentos destinados ao complexo florestal celulósico mantiveram-se em ascensão, como exposto a seguir, sendo a referida década o período com o maior ciclo de investimentos do setor no Brasil. O resultado foi a expansão e modernização da indústria e a introdução de um novo segmento industrial produtor celulose de mercado (SOTO, 1992). Aliás, é a partir da referida década, tendo em vista ao arcabouço legal instituído e aos incentivos fiscais/tributários concedidos, que se inicia o processo de subordinação do cultivo de eucalipto à indústria de papel e celulose.

Um dos principais instrumentos que garantiu a disseminação dos incentivos à atividade foi o decreto-lei n. o 1.376 de 12 de dezembro de 1974. Através deste decreto o governo federal estabeleceu novos mecanismos de negociação e distribuição de incentivos a diversos setores, por meio da criação de fundos de investimentos, dentre os quais destaca-se o Fundo de Investimentos Setoriais - FISET ${ }^{10}$. Direcionado aos setores de pesca, turismo e florestamento/ reflorestamento, o FISET estruturava-se em um sistema de incentivos fiscais aplicados por pessoa jurídica até o máximo de $17,5 \%$ de seu imposto de renda devido na fonte para projetos realizados na região centro-sul do país, ou 25\% para aqueles situados nas regióes Norte e Nordeste (BARBOSA, 2008; SOTO, 1992). Apesar de se fundamentar no tripé pesca, turismo e "florestamento/reflorestamento”, devido à enorme demanda por matéria-prima colocada pelo complexo florestal celulósico e pela indústria siderúrgica, o carro chefe do FISET consistia no setor de florestamento/reflorestamento (FISET - florestamento/reflorestamento) (BARBOSA, 2008).

Em 1974 a economia brasileira apresentava dificuldades, devido ao choque do petróleo ocorrido no final de 1973, que foi responsável por elevar não só os preços do petróleo e de seus derivados, mas também de diversas matérias-primas, bens intermediários e bens de capital. Esta conjuntura desencadeou uma forte redução da atividade econômica no mundo (Mantega, 1997). 
Para enfrentá-la o governo brasileiro criou o II Plano Nacional de Desenvolvimento - II PND. Este plano priorizou a complementação da estratégia de substituição de importações e a expansão das exportaçôes, principalmente de produtos manufaturados. Foi na esteira deste Plano que três meses depois do lançamento do II PND foi criado o I Programa Nacional de Papel e Celulose - I PNPC que vigorou até 1984 (JUVENAL \& MATTOS, 2003).

O objetivo do I PNPC era tornar o Brasil autossuficiente na produção de papel e celulose. Neste sentido, delegava ao Ministério da Agricultura a responsabilidade da promoção de ações destinadas a atender estes objetivos (HILGEMBERG \& BACHA, 2000; SOTO, 1992). Como o programa foi elaborado em um momento de alta do preço internacional da celulose, o governo federal procurava, por meio dele, também favorecer a geração de excedentes exportáveis, de modo a inserir o país no comércio internacional deste produto. Para tanto, o programa previa a instalação de treze grandes plantas industriais produtoras de papel e celulose no país até 1980, por meio de um modelo tripartite com igual participação do Estado, capital privado nacional e capital privado estrangeiro. Das treze plantas previstas, cinco foram implantadas, cabendo ao Estado a responsabilidade pela maior parte do investimento (HILGEMBERG \& BACHA, 2000).

O I PNPC agrupou todas as medidas políticas voltadas ao complexo celulósico florestal, vigentes desde o final dos anos 1960, as articulou formalmente e as complementou. Assim, estabeleceu objetivos, escalas mínimas de produção e metas de exportação, bem como, aperfeiçoou mecanismos operacionais. Além disso, para fortalecer o complexo florestal celulósico, "articulou medidas de política agrícola (...) com industriais; a política de financiamento com medidas de fomento às exportaçôes; medidas para o fortalecimento de grandes grupos empresariais nacionais com uma política de atração do capital externo de risco" (SOTO, 1992, p. 193).

Dentre os aspectos do I PNPC que merecem destaque encontram-se: 1) apoio a articulação entre floresta e indústria; 2) a manutenção das escalas mínimas de produção para novas indústrias, com maior ênfase a produção para exportação, sujeitando a concessão de benefícios ao seu cumprimento; 3) e o papel essencial cumprido pelo sistema BNDES, através do fornecimento de crédito subsidiado de longo prazo, da criação de programas adicionais para a capitalização das empresas privadas nacionais; e da participação acionária direta nos projetos (SOTO, 1992) .

Foi justamente durante o período de vigência do I PNPC que foram construídos ou concretizados grandes projetos fabricantes de celulose de mercado, materializando assim a opção do II PND por uma industrialização menos concentrada regionalmente. Dentre estes projetos destacam-se a 
CENIBRA no estado de Minas Gerais, cuja construção começou em 1975; a Jari nos estados do Pará e Amapá, cuja construção teve início em 1968; e a Aracruz Celulose S/A no estado do Espírito Santo, que iniciou suas operaçóes em 1968, como Aracruz Florestal ${ }^{11}$ (FAILASSE, 1996; HILGEMBERG \& BACHA, 2000). Grande parte dos líderes empresariais do complexo recebeu, concomitantemente, do $\mathrm{BNDE}$, financiamento direto subsidiado, participação acionária do BNDE de até $50 \%$ do capital, créditos oriundos do Financiamento de Máquinas e Equipamentos - FINAME para aquisição de equipamentos nacionais, apoio para a importação de equipamentos e financiamento de acionistas ${ }^{12}$.

Além do financiamento destinado ao parque industrial fabricante de papel e celulose, o I PNPC estabeleceu um conjunto de medidas claramente orientadas à expansão da base florestal da indústria. Para tanto, propôs metas anuais de plantio, que eram calculadas com base nas necessidades industriais de madeira, de modo a garantir as metas na produção de papel e celulose. Assim, é possível constatar que os benefícios e incentivos concedidos pelo I PNPC foram direcionados ao complexo florestal celulósico como um todo, na medida em que abrangiam tanto o segmento de monocultivo de eucalipto, quanto o de fabricação de celulose e papel, fabricação de celulose de mercado e de máquinas e equipamentos destinados a estas indústrias.

Conforme Faillace (1996b) o I PNPC permitiu uma expansão significativa da capacidade industrial do complexo florestal celulósico. Entre 1981 e 1984, o ganho de divisas oriundos da exportação de celulose foi de $320 \%$. Este ganhou representou a conquista do mercado externo, o que permitiu o Brasil, já no final da década de 1970, a abandonar o status de importador e assumir o papel de exportador de celulose, importando apenas papel de imprensa e alguns tipos especiais de papéis de celulose de fibra longa.

Ainda no período de vigência do I PNPC, precisamente em 27 de dezembro de 1976, foi estabelecido o Decreto no 79.046. Este decreto consistia em mais um instrumento legal criado pelo governo federal, com o intuito de regulamentar medidas direcionadas à aplicação de incentivos fiscais destinados ao desenvolvimento florestal no país. Por intermédio deste decreto foi criado no Brasil o Programa de Distritos Florestais-Industriais.

Art. 1‥ Os empreendimentos florestais que possam servir de base à exploração econômica, e contribuir para o desenvolvimento e conservação da natureza, através do florestamento ou reflorestamento, poderão ser objeto dos incentivos, fiscais de que trata este decreto.

$\S 1$ o. Os empreendimentos florestais a que se refere este artigo serão objeto de projetos específicos, anuais, elaborados pelos interessados, os quais deverão ser submetidos previamente à aprovação do Instituto Brasileiro de Desenvolvimento 
Florestal - IBDF, a fim de poderem ser considerados aptos a receber os incentivos fiscais.

Art. 2․ Os empreendimentos florestais poderão ser realizados por pessoas físicas ou jurídicas, residentes ou domiciliados no País, em terras de que tenham justa posse, a título de proprietário, usufrutuário, ou de que, de outra forma tenham o uso, inclusive como locatário ou como datários.

Art. 3․ As empresas especializadas em florestamento e reflorestamento, previamente registradas no $\mathrm{IBDF}$, poderão executar, mediante contrato, os serviços constantes do presente Regulamento.

Art. 5․ Competirá ao IBDF, ouvida a Comissão de Política Florestal, delimitar as Regiốes Prioritárias para Florestamento.

Art. 6o. Por indicação também do IBDF serão delimitadas, mediante Decreto, como Distritos Florestais Industriais, as áreas onde, na data da publicação deste regulamento, já exista em funcionamento ou em implantação, indústria que utilize a madeira como insumo principal.

$\S 1$ ‥ A futura delimitação de novos Distritos Florestais-Industriais será proposta ao Presidente da República em exposição conjunta dos Ministros da Agricultura, da Indústria e do Comércio do Interi--or e da Secretaria de Planejamento da Presidência da República.

$\S 2$ 2 . Na hipótese do parágrafo anterior, o Conselho de Desenvolvimento Industrial - CDI só aprovará projetos localizados nas Regióes Prioritárias para Florestamento e, e em articulação com o IBDF, dará preferência aos casos em que a empresa industrial seja responsável também pelo respectivo projeto de florestamento ( BRASIL, 1976).

Conforme constata-se nos artigos e parágrafos apresentados acima, extraídos do Decreto no 79.046, o objetivo do decreto era selecionar, por intermédio do IBDF, áreas prioritárias para a realização de cultivos florestais, que receberiam os recursos advindos dos incentivos fiscais, a fim de conciliar a oferta e a demanda de matéria-prima de origem florestal. Contudo, pode-se interpretar também, que os distritos florestais objetivavam acelerar e ampliar a concessão de recursos financeiros e políticos, de modo a atender à demanda industrial por madeira e derivados, criando polos florestais capazes de gerar ou sustentar polos industriais. Além de regulamentar a criação de distritos florestais, o Decreto no 79.046 priorizou a verticalização floresta-indústria ${ }^{13}$ para a concessão dos incentivos fiscais ao monocultivo de árvores exóticas (GONÇALVES, 2001).

Assim, a partir dos incentivos concedidos e da legislação instituída, estas grandes plantas industriais compraram diversas áreas, muitas delas das antigas reflorestadoras independentes. Isto permitiu que o segmento organizado em um verdadeiro complexo, ampliasse, significativamente, suas 
reservas florestais, principalmente de eucalipto, em diversas regióes brasileiras e, por conseguinte, garantisse o controle da terra, elemento fundamental para sua manutenção, completando, desta forma, o processo de subordinação do monocultivo de eucalipto à indústria de papel e celulose (FAILLACE, 1996, GONÇALVES 2001; SOTO, 1992).

A década de 1980 foi um período de grande aquecimento no segmento mundial fabricante de papel e celulose. O setor alcançou taxas anuais de crescimento de $3,4 \%$, e o consumo mundial de papel passou de 171 milhóes de toneladas em 1980 para 239 milhóes de toneladas em 1990. Ainda assim, o crescimento da demanda internacional por papel, estimulado pela difusão da informática - devido à massificação de copiadoras, impressoras, aparelhos de fax - e da mídia impressa, foi maior que o ritmo da oferta. Esta conjuntura elevou a cotação dos preços de celulose e de papel no mercado internacional que, no final de 1989 , atingiram o valor de US\$ 840,00 por tonelada. Este cenário, aliado a projeçóes da FAO que apontavam para um aumento do consumo mundial de papel de, aproximadamente, $3 \%$ ao ano até 1995 , motivaram grandes investimentos no setor, bem como o aumento da produção (FAILLACE, 1996).

Diante da conjuntura favorável no mercado internacional, a crise econômica que assolava o Brasil neste período não impediu a continuidade da realização de incentivos e investimentos públicos no complexo florestal celulósico. Deste modo, na segunda metade da década de 1980 iniciou-se um novo ciclo de investimentos direcionados à modernização e ampliação da capacidade produtiva das indústrias. Para organizar estes investimentos foi criado em 1987 o II PNPC que vigorou até 1995.

Diferentemente da primeira edição do programa, o II PNPC não possuía um conjunto articulado de medidas, contava apenas com um plano de investimentos produtivos. O principal objetivo do II PNPC era a obtenção de financiamento de longo prazo, de modo a favorecer a geração de um novo ciclo de investimentos no setor. Estruturado, basicamente, através de recursos do BNDES, o II PNPC previa investimentos de cerca de US\$ 9,6 bilhóes para o período de 1987 a $1995^{14}$. Destes, 6,4 bilhôes seriam destinados à ampliação da produção de celulose e o restante seria direcionado à expansão da produção de papel, sobretudo, de imprimir e escrever (HILGEMBERG \& BACHA, 2000; SOTO, 1992).

Assim, mesmo com a crise da dívida externa brasileira, que afetou os investimentos realizados pelo Estado, a década de 1980 consistiu em um dos períodos em que o complexo florestal celulósico mais cresceu no país, pelas razóes apontadas anteriormente, situação que se transformou apenas no final desta mesma década, cujos impactos foram sentidos nos anos 1990. 
Conforme Soto (1992) o segmento atravessou a "década perdida15", com um crescimento médio de 4,8\% ao ano, determinado, em grande medida, pelo crescimento da demanda externa. Entre 1980 e 1990 a produção de papel aumentou de 3,3 para 4,7 milhóes de toneladas (42\%) e a produção de celulose de fibra curta passou de 2,1 para 2,7 milhôes de toneladas (29\%). O valor total das exportaçóes de papel e celulose que em 1978 era de US\$ 110 milhões chegou a US\$ 765 milhões em 1984 e a US\$ 1,4 bilhão em 1988.

O final da década de 1980 marca uma reviravolta na conjuntura vivenciada pelo complexo florestal celulósico brasileiro. A recessão que assolou as economias centrais no final da década de 1980 atingiu o setor de papel e celulose mundial. Deste modo, o período de alta dos preços no mercado internacional, foi sucedido por um período de baixa entre os anos de 1990 e 1993, onde preços da celulose despencaram, atingindo uma média de US\$ 350 por tonelada no final de 1993 (FAILLACE, 1996b). Por outro lado, os incentivos financeiros e fiscais dos antigos programas de expansão da produção deixaram de existir.

O enfrentamento da crise experimentada a partir da segunda metade dos anos 1980 exigiu reformulações significativas nas políticas administrativa, financeira e organizacional das indústrias do complexo florestal celulósico, que direcionaram seus esforços para aumentar as exportaçóes e reduzir os custos. Estas reformulações se intensificaram nos anos 1990, década marcada pela ruptura definitiva da política econômica e industrial brasileira com o modelo de substituição de importaçôes (JUVENAL \& MATTOS, 2002).

Nesse contexto ocorreram diversas aquisições, fusões e formação de joint ventures entre empresas de capital nacional ou entre empresas de capital nacional e estrangeiro, ocasionando um processo de concentração de capital no setor ${ }^{16}$. Houve um crescimento da participação do capital externo direto ou através de empréstimos no padrão de financiamento do setor. A abertura do capital das empresas passou a ser analisada com menor desconfiança pelos seus controladores. Ao mesmo tempo, a gestão familiar começou a ser substituída pela gestão profissional, em especial nos grandes fabricantes de celulose e nos grupos exportadores (FAILLACE, 1996; JUVENAL \& MATTOS, 2002).

Assim, as empresas do complexo florestal celulósico abandonaram as exigências do desenvolvimento planejado no país, passaram a observar as inovações financeiras, as necessidades de expansão das plantas industriais e a obedecer aos ritmos definidos pelo avanço dos mercados. Tal conjuntura favoreceu a desnacionalização do controle e da gestão administrativa das empresas, cuja maioria passou a integrar o mercado de ações (BARCELOS, 2010). 
O resultado foi a conformação de um segmento produtor de commodities voltado para o mercado internacional. Desta forma, se até a década de 1970, aproximadamente, $60 \%$ da produção de celulose era controlada por pequenas e médias empresas, nos anos 1990, a situação se transforma, de modo que grandes empresas, com escalas de produção superiores a $500 \mathrm{mil} / \mathrm{t} / \mathrm{celulose} /$ ano, passam a dominar o setor (PEDREIRA, 2008).

\section{CONSIDERAÇÕES FINAIS}

Este trabalho resgatou as condiçóes que favoreceram a utilização do eucalipto como matéria-prima principal para a indústria de papel e celulose no Brasil. A constatação da possibilidade de utilização do eucalipto e, por conseguinte de celulose de fibra curta, na fabricação de papéis no final da década de 1950 , provocou uma guinada na indústria brasileira deste segmento até então, bastante rudimentar. Esta, por sua vez, passou a fabricar a sua matéria-prima, antes, majoritariamente importada.

$\mathrm{O}$ artigo destacou como se estruturaram os incentivos fiscais destinados ao cultivo de eucalipto e a fabricação de papel e celulose, bem como, salientou brevemente, os caminhos que conduziram a sua extinção na segunda metade dos anos 1980. Assim, constatou-se que a consolidação do complexo florestal celulósico no Brasil tem como fator fundamental a articulação entre interesses agrários (atividade florestal) e industriais, mediados pelo Estado que, por sua vez, esteve e se mantém vinculado ao complexo florestal celulósico, ora como orquestrador de interesses; por vezes como investidor; ou então na condição de promotor de políticas públicas.

Devido às condiçôes favoráveis ao cultivo de eucalipto presentes no país e, sobretudo, em virtude dos incentivos governamentais destinados a introdução dos plantios e não só a fabricação de papel, mas também a produção de celulose para exportação, o Brasil se tornou um dos maiores produtores de celulose de fibra curta do mundo, sendo a Aracruz Celulose S/A a maior empresa do mundo neste segmento.

Apesar, do trabalho não ter como objetivo a discussão sobre os impactos sociais e ambientais decorrentes da expansão do cultivo de eucalipto e do segmento fabricante de papel e celulose no Brasil, ressalta-se que estes processos desencadearam país afora uma série de impactos como, por exemplo, a expulsão de pequenos agricultores, povos indígenas e remanescentes de quilombos de suas terras; alteraçóes no emprego rural; devastação de reservas de Mata Atlântica; contaminação das águas por agrotóxicos e homogeneização da paisagem. 


\section{Notas}

1 Edmundo Navarro de Andrade foi ministro interino da Agricultura no governo Getúlio Vargas, substituindo o ministro Juarez Távora duas vezes, de 19 de agosto a 4 de outubro de 1933 e de 9 de janeiro a 18 de fevereiro de 1934 (HASSE, 2006).

${ }^{2}$ https://bit.ly/3bKhSJ2. Acesso em: 20 abr. 2020.

3 O ferro-gusa, principal matéria-prima do aço, é o produto imediato da redução do minério de ferro pelo coque ou carvão e calcário em um alto forno. Fonte: http://www.ifba.edu.br/metalografia/ arq/gusa.pdf. Acessado em 20 de fev. 2020.

${ }^{4}$ O Plano de Metas foi um programa de desenvolvimento elaborado em 1956, pelo Conselho de Desenvolvimento, órgão subordinado ao Presidente da República, e começou a ser aplicado em 1957. Neste plano cinco áreas foram priorizadas para as quais investimentos públicos e privados deveriam ser direcionados, eram elas: transporte, energia, alimentação, educação e indústria básica. Celulose e papel era um dos segmentos da indústria de base contemplados no Plano (JUVENAL \& MATTOS, 2002).

${ }^{5}$ O IPEF consiste em uma associação sem finalidade econômica fundada em 1968 a partir de um convênio entre pesquisadores da ESALQ/USP e indústrias fabricantes de papel e celulose. Seu objetivo é desenvolver técnicas destinadas a promoção da melhoria da qualidade e produtividade da atividade florestal.

${ }^{6}$ https://bit.ly/2YgBqke. Acesso em: 20 fev. 2020.

${ }^{7}$ A legislação que regulamentou a concessão de incentivos fiscais à atividade florestal exigia que 1\% do valor de implantação dos projetos florestais fosse destinado ao financiamento de pesquisas relacionadas à própria atividade florestal, sendo o repasse feito a partir das empresas privadas. Isto explica a forma de criação do IPEF e a prioridade de suas pesquisas, orientadas para as atividades privadas industriais (SOTO, 1992).

${ }^{8}$ De modo geral, o fomento florestal trata-se de um modelo de integração produtiva fundamentado em um contrato de parceria entre empresas e produtores, cuja maioria é composta por agricultores de base familiar. Esta estratégia não possui um modelo único, assim sendo, para cada região e para cada indústria há diversas formas de contrato. Todavia, pode-se dizer que em geral, nos programas de fomento florestal as empresas fornecem ao produtor integrado mudas, insumos e assistência técnica. Este, por sua vez, deve produzir eucaliptos em determinada área de sua propriedade para serem vendidos para a mesma. Os custos decorridos do plantio, tratos culturais, transporte da colheita até a os pontos estabelecidos pela indústria, devem ser arcados pelo produtor.

${ }^{9}$ Pasta mecânica destinada a fabricação de jornais, revistas e cartões.

${ }^{10}$ Os outros dois fundos criados por meio do referido decreto foram: o Fundo de Investimentos do Nordeste - FINOR, o Fundo de Investimentos da Amazônia - FINAM.

${ }^{11}$ Neste período também houve a expansão de indústrias já em funcionamento, como a Klabin, a Suzano e a Simão, todas em São Paulo (FAILLACE, 1996).

12 Faillace (1996) observa o setor fabricante papel e celulose, para equipar suas indústrias se valeu principalmente da importação de equipamentos, que se configurou no principal item de investimento.

${ }^{13}$ A verticalização, neste caso, significa que a empresa passa a controlar não apenas o processo fabril, mas também outros estágios necessários à produção, como por exemplo, a obtenção de matériaprima, atividades de mercado antes atribuídas a outras firmas, dentre outros processos econômicos tecnologicamente distintos. Assim, corresponde à adição de uma atividade anterior ou posterior ao processo de produção e distribuição, de modo que as novas atividades ficam "verticalmente" relacionadas com as já existentes. Algumas empresas chegam a ter o controle de todo o processo produtivo, desde o suprimento de matéria-prima à comercialização do produto final (CARVALHO et al. 1993).

${ }^{14}$ Conforme Soto (1992) a previsão era que entre 50\% e 60\% dos recursos necessários para a execução do II PNPC seriam proporcionados pelo BNDES.

${ }^{15}$ Como ficou conhecida a década de 1980 no Brasil, em virtude da grave crise econômica que assolou o país.

${ }^{16}$ Joint venture ou empreendimento conjunto é a denominação dada a uma associação de empresas, que pode ser definitiva ou não, com fins lucrativos, destinada a explorar determinados negócios, sem que nenhuma delas perca sua personalidade jurídica. A Fibria Celulose S/A, por exemplo, é detentora da Veracel - uma joint venture com a sueco-finlandesa StoraEnso. 


\section{Referências Bibliográficas}

ANDRADE, E. N. (1961). O Eucalipto. São Paulo: FAO/ONU.

BACHA, C. J. C. (2004). O Uso de Recursos Florestais e as Políticas Econômicas Brasileiras - Uma Visão Histórica e Parcial de um Processo de Desenvolvimento. Estudos Econômicos., São Paulo, abr. /jun., v. 34, n. 2., p. 393-426. Disponível em: https:// bit.ly/2VMıHVP. Acesso em: 20 jan. 2020.

BARBOSA, R. I. (2008). "O fim do FISET em Roraima e a perpetuação do modelo de florestamento no Lavrado". INPA. Roraima: INPA. Disponível em: https://bit. ly/3aFnkvm. Acesso em: 20 fev. 2020.

BARCELOS; E. A. S. (2010). A espacialidade das plantações arbóreas e a integração agroindustrial: O Programa Produtor Florestal e seus (im)pactos na agricultura capixaba. 316 f. Dissertação (Mestrado em Geografia) - Universidade Federal Fluminense, Niterói.

BRASIL. Lei $\mathrm{N}^{\circ} 4.771$, de 15 de setembro de 1965. Institui o novo Código Florestal. Disponível em: https://bit.ly/3aLB4of. Acesso em: 20 jan. 2020.

. Decreto-Lei n ${ }^{\circ} 289$, de 28 de fevereiro de 1967. Cria o Instituto Brasileiro do Desenvolvimento Florestal e dá outras providências. Disponível em: https://bit. ly/35cvURf. Acesso em: 23 fev. 2020.

Lei ${ }^{\circ} 5.106$, de 2 de setembro de 1966. Dispõe sôbre os incentivos fiscais concedidos a empreendimentos florestais. Disponível em: https://bit.ly/3bKiFKo. Acesso em: 23 fev. 2020.

. Decreto $n^{\circ} 79.046$, de 27 de

Dezembro de 1976.Dispõe sobre aplicação dos incentivos fiscais para o Desenvolvimento Florestal do País. Disponível em: https://bit.ly/35ioBY. Acesso em: 22 fev. 2020.

CARVALHO, F. C. Et al. (1993). Estudo da integração vertical na agroindústria sucroalcooleira no estado de São Paulo, 1970-92. Agricultura em São Paulo, São Paulo, v. 40, n. 1, p. 157-182. Disponível em:
ftp://ftp.sp.gov.br/ftpiea/ASP9-0193.pdf. Acesso em: 23 fev. 2020.

DELGADO, G. C. (1985). Capital Financeiro e Agricultura no Brasil. Campinas: UNICAMP.

DIAS, C. R. S. (2007). Geografia Histórica Ambiental: uma geografia das matas brasileiras. 2007. 227f. Tese (Doutorado em Geografia) - Universidade Federal Fluminense, Niterói.

FAILLACE, S. (1996). Complexo florestalcelulósico no Brasil: histórico e estratégias empresariais. Rio de Janeiro: Amigos da Terra/FASE.

(1996b). Uma leitura da indústria de papel e celulose no Brasil sob a perspectiva da sustentabilidade norte-sul. Brasil: sustentabilidade e democracia . Rio de Janeiro: FASE.

FANZERES, A. (2005). Temas Conflituosos Relacionados à Expansão da Base Florestal Plantada e Definição de Estratégias para Minimização dos Conflitos Identificados. Relatório Final de Consultoria. Projeto MMA/FAO/TCP/BRA/2902: Brasília.

GONÇALVES, M. T. (2001). Nós da madeira: mudança social e trabalhadores assalariados das plantações florestais nos Vales do Aço/Rio Doce de Minas Gerais. 2001. Tese (Doutorado em Desenvolvimento, Agricultura e Sociedade) - Universidade Federal do Rio de Janeiro, Rio de Janeiro.

HASSE, G. (2006). Eucalipto: histórias de um imigrante vegetal. Porto Alegre: Já Editores.

HILGEMBERG E. M.; BACHA, C. J. C. (2000). As pressões ambientais e as alterações na demanda e oferta mundial de celulose. Pesquisa \& Debate, São Paulo, volume 11, número 2, p. 67-92. Disponível em: https://bit.ly/3aJqRsE. Acesso em: 17 jan. 2020.

JUVENAL, T. L.; MATTOS, R. L. G. (2003). O Setor de Celulose e Papel. Setorial 04 Celulose e Papel. BNDES. 21p. 
KENGEN, S. (2001). A Política Florestal Brasileira: uma perspectiva histórica. IPEF, SIAGEF. Porto Seguro, jul. Disponível em: https://bit.ly/2Sgxv34. Acesso em: 23 fev. 2020.

LOPES, C. R. A.; CONTADOR, C. R. (1998). Análise da Indústria de Papel e Celulose no Brasil. Rio de Janeiro. 1998. Disponível em: https://bit.ly/3flelt2. Acesso em: 15 abr. 2020.

MANTEGA, G. (1997). O Governo Geisel, O II PND e os economistas. EAESP/FGV/ NPP - Núcleo de pesquisas e publicações. Relatório de Pesquisa n. 3. Disponível em: https://bit.ly/2VIT7Hr.. Acesso em 20 fev. 2020.

MARTINI, J. A. (2004). O plantador de eucaliptos: A questão da preservação florestal no Brasil e o resgate documental do legado de Edmundo Navarro de Andrade. 2004. 261 f. Dissertação (Mestrado em História Social) - Faculdade de Filosofia, Letras e Ciências Humanas da Universidade de São Paulo, São Paulo.

MAY, Tim. (2004). Pesquisa Social: Questões, métodos e processos. Trad. Carlos Alberto Netto Soares. $3^{\mathrm{a}}$ ed. Porto Alegre: Artmed.

MEDEIROS, R. (2006). Evolução das tipologias e categorias de áreas protegidas no Brasil. Ambiente \& Sociedade, v. 9, n. 1, p. 41-64. Disponivel em: https://bit. ly/35eCK8B. Acesso em: 15 fev. 2020. MIRANDA, R. E. S. (2008). Impactos ambientais decorrentes dos resíduos gerados na Produção de papel e celulose. 2008. 37 f. Monografia (Graduação em
Engenharia Florestal) - Universidade Federal Rural do Rio de Janeiro,

Seropédica, 2008.

MORA, A. L.; GARCIA, C. H. (2000). A Cultura do Eucalipto no Brasil. São Paulo: Sociedade Brasileira de Silvicultura.

PEDREIRA, M. S. (2008). O complexo florestal e o extremo Sul da Bahia: Inserção competitiva, limites e possibilidades do desenvolvimento regional. $163 \mathrm{f}$. Tese (Doutorado em Desenvolvimento, Agricultura e Sociedade) - Universidade Federal Rural do Rio de Janeiro, Rio de Janeiro.

QUEIROZ, L. R. de S; BARRICHELO, L. E. G. (2000). A Celulose de Eucalipto - Uma oportunidade brasileira. São Paulo: Avis Brasilis Editora.

SAMAPAIO, A. N. (1961). O eucalipto. São Paulo: Edição Cia. Paulista de Estradas de Ferro, 1961.

SOTO, F. (1992). Da indústria de papel ao complexo florestal no Brasil, o caminho do corporativismo tradicional ao neocorporativismo. 305 f. Tese(Doutorado em Economia) - Universidade Estadual de Campinas.

VOLPATO, L. G. (2007). Como escrever um artigo científico. São Paulo. Anais da Academia Pernambucana de Ciência Agronômica, Recife, vol. 4, p.97-115.

ZENI, D. D. S. (1994). A indústria de celulose e o meio-ambiente. Indicadores Econômicos FEE, Porto Alegre, v. 22, n. 2, p. 268-271.

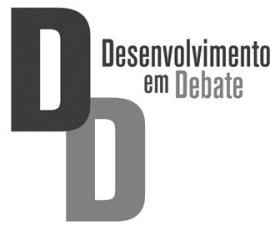

